\title{
REVISTAMARACANAN
}

Artigo

\section{O que a cidade de Ipásia tem a nos dizer sobre pixação? Leituras possíveis de As Cidade Invisíveis, de Ítalo Calvino, e São Paulo/SP}

\author{
What does the city of Ipasia have to tell us about graffitti? Possible readings of \\ Invisible Cities of Ítalo Calvino and São Paulo/SP
}

Bianca Siqueira Martins Domingos*

Centro Universitário Teresa D'Ávila Lorena, São Paulo, Brasil

Fabiana Felix do Amaral e Silva** Universidade do Vale da Paraíba São José dos Campos, São Paulo, Brasil Valéria Regina Zanetti ${ }^{* * *}$ Universidade do Vale da Paraíba São José dos Campos, São Paulo, Brasil

Recebido em: 23 set. 2019.

Aprovado em: 10 dez. 2019.

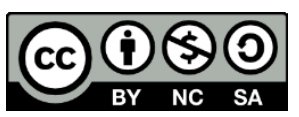

\footnotetext{
* Professora contratada do Centro Universitário Teresa D'Ávila; Doutoranda do Programa de Pós-Graduação em Planejamento Urbano e Regional da Universidade do Vale do Paraíba, com bolsa CAPES. Mestre em Desenvolvimento, Tecnologias e Sociedade pela Universidade Federal de Itajubá; graduada em Administração pelo Centro Universitário Teresa D'Ávila. (biancasiqueira.m@gmail.com)

(iD) http://orcid.org/0000-0001-9249-4754

(9) http://lattes.cnpq.br/7210085651960891

** Professora Adjunta da Universidade do Vale do Paraíba, atuando no Programa de Planejamento Urbano e Regional. Doutora e Mestre em Ciências da Comunicação pela Universidade de São Paulo; graduada em Arquitetura e Urbanismo pela Universidade Presbiteriana Mackenzie. Realizou estágio de pós-doutorado na Universidade de São Paulo e na Universidade do Vale do Paraíba. (fabiana.amaral@gmail.com)
(iD) https://orcid.org/0000-0002-5754-9745
(9) http://lattes.cnpq.br/9584609707431515

*** Professora Assistente da Universidade do Vale da Paraíba, atuando nos cursos de graduação em História e Geografia e no Programa de Planejamento Urbano e Regional. Doutora em História Social pela Pontifícia Universidade Católica de São Paulo; Mestre em História Social pela Pontifícia Universidade Católica do Rio Grande do Sul; graduada em História pela Universidade Federal de Ouro Preto. (vzanetti@univap.br)
(iD) https://orcid.org/0000-0003-2968-9342
(9) http://lattes.cnpq.br/5861966066047404 


\title{
Resumo
}

O tecido urbano da cidade de São Paulo nos fornece um espectro de possibilidades de leituras conceituais, simbólicas e interdisciplinares, em que a pixação se constitui como um importante elemento visual na urbe. Ao circularmos pela cidade observamos nos prédios, paredes e espaços construídos, frases e símbolos monocromáticos que se mesclam com a paisagem urbana. 0 objetivo deste artigo é construir articulações entre Ipásia, uma das cidades do livro As Cidades Invisíveis, de Ítalo Calvino, e as pixações da cidade de São Paulo, a partir dos nexos entre as simbologias impressas nos territórios e práticas urbanas das duas cidades. A perspectiva teóricometodológica é amparada por referencial vinculado à interpretação dos símbolos, do imaginário, das subjetividades, estruturada na semiótica do ambiente simbólico e na fenomenologia. Os símbolos na forma de pixação são, de certo modo, parte da experiência de se visitar/viver em São Paulo, cujas representações imagéticas, memórias e ressignificações dialogam com o urbano real e com o imaginado mundo das cidades invisíveis de Calvino.

Palavras-chave: Pixação. As Cidades Invisíveis. Símbolos. Cultura e Território. Planejamento Urbano.

\begin{abstract}
The urban tissue of the city of São Paulo provides us a spectrum of possibilities of conceptual, symbolic and interdisciplinary readings, in which spray graffitis constitutes an important visual element in the city. As we walk through the city, we observe in the buildings, walls and in the built spaces phrases and monochrome symbols that blend with the landscape of the city. The objective of this article is to construct articulations between the invisible city of Ipásia, from the book Invisible Cities by Ítalo Calvino, and the spray graffitis from the city of São Paulo, addressing the nexus evidenced in the printed symbologies in both their territories and practices. The theoretical-methodological perspective is supported by reference linked to the interpretation of symbols, the imaginary, the subjectivities, structured in the semiotics of the symbolic environment and in phenomenology. The symbols in the form of spray graffitis are, in a way, part of the experience of visiting / living in São Paulo. Among imagery representations, memories and resignifications, Ipásia and São Paulo dialogue with the real urban and the imagined.
\end{abstract}

Keywords: Graffiti. The Invisible Cities. Symbols. Culture and Territory. Urban Planning. 
Pixar é crime num país onde roubar é arte.

DjanIvson Silva. ${ }^{1}$

Os símbolos formam uma língua, mas não aquela que você imagina conhecer.

Ítalo Calvino. ${ }^{2}$

\section{Introdução}

O livro As Cidades Invisíveis, de Ítalo Calvino, traz como protagonistas 55 cidades imaginárias, todas com nomes femininos, como Ipásia, Despina, Zirma, Isaura, Cecília e Leônia. O livro foi inspirado na viagem de Marco Polo, mercador veneziano que, na Idade Média, por 17 anos, exerceu funções diplomáticas no imenso Império Mongol de Kublai Khan, com a obrigação de relatar ao imperador as maravilhas das extensas terras que não podia contemplar.

As Cidades Invisíveis de Calvino vão além dos diálogos de Polo e Khan e dos fatos ocorridos no século XIII. As 55 cidades retratadas por Calvino, agrupadas em 11 temas, como "as cidades e os símbolos", "as cidades e a memória", "as cidades e o céu", "as cidades e o mortos" etc., são lugares imaginários que fornecem subsídios para múltiplas leituras do espaço urbano a partir de aproximações temporais e territoriais, reais e imaginárias, do possível e do impossível. Das conexões possíveis, é plausível encontrar as cidades invisíveis nas cidades visíveis, assim como é possível perceber várias cidades visíveis nas invisíveis de Calvino.

A cidade de Ipásia, por exemplo, incluída no grupo "As cidades e os símbolos", um dos 11 grupos elucidados por Calvino, fornece subsídios para o estudo da linguagem da subconsciência coletiva e da imagem da cidade. Tendo como dispositivo para reflexão a cidade invisível de Ipásia e como recurso de análise a pixação, intervenção visual urbana carregada de simbologia, busca-se, por meio das intervenções artísticas de resistência, interpretar os simbolismos dos fenômenos urbanos, abordando os nexos evidenciados nas simbologias impressas nos territórios e práticas da cidade de São Paulo e de Ipásia.

A grafia da palavra pixação, com "x" e não com "ch", conforme rege a ortografia oficial, será adotada neste ensaio teórico "para respeitar o modo como os pixadores escrevem o termo que designa sua prática. Esse modo particular de grafar é apontado por alguns pixadores como uma maneira de diferenciar-se do sentido comum atribuído à norma culta da

\footnotetext{
${ }^{1}$ LASSALA, G. Em nome do pixo: a experiência social e estética do pichador e artista DjanIvson. 2014. Tese. (Doutorado em Arquitetura e Urbanismo) - Universidade Presbiteriana Mackenzie, São Paulo, p. 15. ${ }^{2}$ CALVINO, I. As cidades invisíveis. São Paulo: Companhia das Letras, 1990, p. 21.
} 
língua: pichação. "Pixar" seria diferente de "pichar", pois este último termo designaria qualquer intervenção escrita na paisagem urbana, enquanto o primeiro remeteria às práticas desses jovens que deixam inscrições grafadas de forma estilizada no espaço urbano". ${ }^{3}$ Grafar a pixação "com x evidencia a assunção de identidade por meio do ato da escrita que traz consigo um modo de vida, de organização, de sociabilidade específica e de apropriação da cidade". ${ }^{4}$

Considerada contravenção penal na legislação federal, estadual e em muitos municípios do Brasil, a pixação domina a paisagem da cidade de São Paulo. Muitos pixadores arriscam suas vidas ao escalarem prédios e adentrarem locais abandonados/perigosos em nome do pixo. Feita com spray, na maioria da cor preta, as intervenções possuem uma tipografia específica de difícil leitura. Tema de documentários, livros e estudos científicos, a pixação vem sendo discutida nos últimos anos por diversas perspectivas e diferentes áreas do conhecimento.

Este ensaio teórico é derivado de uma pesquisa de Doutorado ainda em curso no âmbito de um Programa de Pós-Graduação em Planejamento Urbano e Regional, cuja investigação tem como temática central o graffiti e as narrativas urbanas que permeiam essas intervenções artísticas em municípios da Região Metropolitana do Vale do Paraíba e Litoral Norte do Estado de São Paulo.

A perspectiva metodológica ensaiada no artigo estabelece relações entre a literatura e a realidade concreta na busca de diálogos possíveis que indicam a leitura da "paisagem" como campo de estudo do Planejamento Urbano, amparada pela semiótica do ambiente simbólico, cuja fenomenologia é base para o estudo do imaginário social e das subjetividades coletivas. As observações das pixações na cidade de São Paulo se deram a partir de caminhadas pelo centro da cidade permeadas por um olhar fenomenológico sobre esses espaços urbanos, tomando o caminhar como forma de vivenciar, conhecer e explorar a paisagem da cidade perpassada por um olhar poético, construtivo, reflexivo e, ao mesmo tempo, exploratório e estético. $^{5}$

Um dos nexos entre a pixação de São Paulo e a da cidade de Ipásia se ancora na centralidade que os símbolos têm em ambas. Apesar da cidadela de Ipásia não possuir a dimensão da cidade de São Paulo, é possível estabelecer entre elas algumas aproximações. A música, assim como os símbolos das paisagens das duas cidades, forma uma língua desconhecida. Do invisível para o visível, as fronteiras difusas da cidade de São Paulo e de Ipásia se conectam, possibilitando múltiplas leituras.

\footnotetext{
3 PEREIRA, A. B. As marcas da cidade: a dinâmica da pixação em São Paulo. Lua Nova, São Paulo, n. 79, p. 143-162, 2010, p. 143.

${ }^{4}$ PIRES, Á. O. S. A pichação como apropriação da cidade: o pixador como formador do cenário urbano. 2017. Dissertação (Mestrado em História Social da Cultura) - Universidade Federal de Minas Gerais, Belo Horizonte, p. 13.

${ }^{5}$ CARERI, F. Walkscapes, o caminhar como prática estética. Barcelona: Gustavo Gili, 2013.
} 


\section{Linguagens e Símbolos: Pixações de São Paulo}

Lembrar-se da paisagem urbana de São Paulo sem as pixações é um incompleto exercício de memória. Efervescente e alvo de polêmicas, as pixações são objeto de estudo de diversas áreas do conhecimento, como a Sociologia, a Arquitetura e Urbanismo, o Planejamento Urbano e Regional, a Geografia e o Design. Presente no nosso cotidiano e na imagem da cidade, "cada indivíduo tem uma imagem própria e única [...] mas que se aproxima da imagem pública". ${ }^{6}$ Para Milton Santos, a paisagem é tudo o que nós vemos e o que a nossa visão alcança no domínio do visível, e "não é formada apenas de volumes, mas também de cores, movimentos, odores, sons [...]. A paisagem é um conjunto heterogêneo de formas naturais e artificiais; é formada por frações de ambas seja quanto ao tamanho, volume, cor ou qualquer outro critério". ${ }^{7}$

Em meio a múltiplos elementos físicos da imagética urbana, como as vias, limites, bairros, cruzamentos e pontos marcantes, o pixo se destaca como "uma manifestação estética de parte da população jovem das periferias. Trata-se da grafia estilizada nos espaços públicos da cidade da qual se referem, quase sempre, à denominação de um grupo de jovens ou ao apelido de um pixador individual", e possui uma tipografia peculiar, de "traços retos e angulosos". ${ }^{8}$ Pode ser definido, também, como um "tipo de intervenção urbana ilegal nativa de São Paulo" praticada por jovens de bairros periféricos que, "em busca de notoriedade, se arriscam nessa modalidade ao escalar edificações para carimbar suas marcas em lugares de grande visibilidade". ${ }^{9}$

No espaço cultural Farol Santander, na cidade de São Paulo, a exposição "Lendo a Cidade: Riscos e Rabiscos" (de 12 de julho de 2019 a 03 de novembro de 2019), sob a curadoria de Leonel Kaz, mostra os diferentes tipos de letras do mundo. Na referida exposição, a tipografia do pixo é abordada como uma expressão visual paulistana em que os jovens da periferia escrevem o nome de seus grupos pelas ruas e no topo dos edifícios com letras magras, altas e espremidas, como os prédios que precisam escalar. A tipografia urbana paulistana, por meio dos pixos, apresenta-se como singular, mergulhada em linguagens e símbolos próprios das narrativas dos sujeitos que habitam a cidade.

\footnotetext{
${ }^{6}$ LYNCH, K. A imagem da cidade. Lisboa: Edições 70, 1970, p. 57.

7 SANTOS, M. Metamorfoses do espaço habitado. Fundamentos teóricos e metodológicos da Geografia. São Paulo: Hucitec, 1996, p. 61.

8 PEREIRA, A. B. As marcas da cidade... Op. cit., p. 143.

${ }^{9}$ LASSALA, G. Em nome do pixo... Op. cit., p. 7.
} 
Figura 1 - Edifício Elisa, no Centro de São Paulo, 2010.

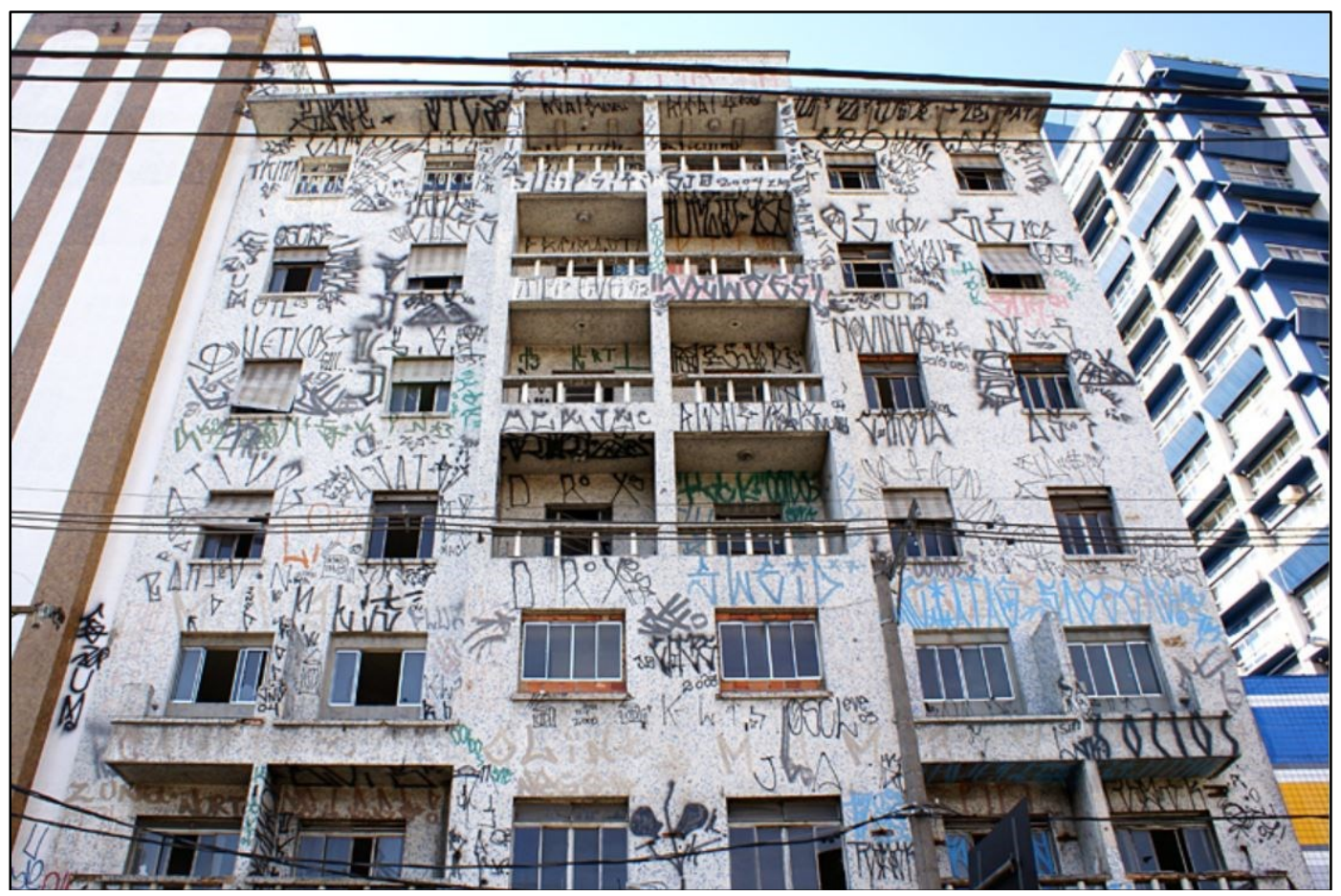

Fonte: Edifício Elisa. São Paulo Antiga. (Site). Disponível em: http://www.saopauloantiga.com.br/edificioelisa/. Acesso em: 2 dez. 2019.

Como "forma de arte plástica pictórica", pode-se dizer que o homem já deixava suas marcas "desde o período neolítico, marcando as paredes das cavernas e grutas com imagens e símbolos". ${ }^{10}$ Segundo Gitahy, na Idade Média e durante a Inquisição, "padres pixavam a parede de conventos de outras ordens que não compactuavam com eles, assim como as inscrições que eram feitas nas paredes das casas de pessoas que se queria difamar". ${ }^{11}$

Além do pixo e do graffiti, outras formas de intervenção em construções privadas e públicas dominam a cena urbana, como o estêncil, forma vazada por meio da qual é usado o spray de tinta; o lambe-lambe, um tipo de cartaz; o ovo de tinta "borroco"; o canetão ou giz de cera; o spray, o extintor de incêndio carregado com tinta e látex; o bomb, grafite rápido ou ilegal ou o grapixo, híbrido das duas técnicas que usa látex como base e preenchimento. ${ }^{12}$

Em uma perspectiva histórica, a pixação emerge no cenário urbano com mais vigor a partir do final da década de 80 e começa a tomar sua forma característica na primeira metade dos anos de 90. Há em outros países escritas semelhantes às pixações, porém não se caracterizam como tal por não terem as mesmas maneiras de socialização entre os seus

\footnotetext{
${ }^{10}$ SILVA, F. L.; ZANETTI, V. São José dos Campos: cidade e graffiti enclausurados (2003-2009). Anais do [...]. XIII Encontro Latino Americano de Iniciação Científica. São José dos Campos: Universidade do Vale do Paraíba, 2009, p. 1; 2.

${ }_{11}$ GITAHY, C. O que é graffiti. São Paulo: Brasiliense, 1999, p. 20.

12 FILARDO, P. R. Pichação (pixo). Histórico (tags), práticas e a paisagem urbana. Arquitextos, São Paulo, ano 16, n. 187.00, dez. 2015.
} 
praticantes e a organização interna próprias do Brasil, apesar de serem semelhantes nas características formais e estilísticas. ${ }^{13}$

A prática de grafar, pichar ou pixar nos muros aos poucos foi se transformando, diversificando-se e ganhando especificidades, de tal forma que, em um dado momento, no final de 1980 e início de 1990, percebe-se que já não se trata da mesma coisa. Não somente quanto ao conteúdo, mas também pelos aspectos formais, sujeitos, lugares, valores e regras que, tal como uma gramática, regem a escrita e apontam para elementos da construção de sentidos. Em meio a variadas escritas não autorizadas o pixo foi se conformando, ganhando corpo próprio e deixando de ser somente meio para deixar uma mensagem. A pixação, aos poucos, despontou como uma prática social organizada em torno do ato de escrever nas paredes envolvendo uma estética, sociabilidades peculiares e maneiras específicas de se colocar no cenário urbano. ${ }^{14}$

Sempre colocados em dualidade, a pixação é marginalizada em relação ao graffiti por ter em sua práxis o perigo e a transgressão, mas em ambos há "um prisma de intencionalidades que se faz presente no efêmero mundo do graffiti e da pixação". ${ }^{15}$ É importante frisar que o graffiti foi descriminalizado no Brasil por meio da Lei No 12.408 , de 25 de maio de 2011. O artigo 65 da Lei no 9.605, de 12 de fevereiro de 1998 diferenciou o graffiti de pixação, mantendo o pixo como crime, cuja pena de detenção é de três meses a um ano, acrescida de multa. Tal distinção passa a caracterizar o graffiti como manifestação artística, desde que seja feito com a autorização do proprietário do imóvel. Esse dispositivo tem um agravante, indicado no $\S 1^{0}$ do artigo, que amplia a punição se "o ato for realizado em monumento ou coisa tombada em virtude do seu valor artístico, arqueológico ou histórico". ${ }^{16}$

Figura 2 - Tipografia da pixação paulistana em destaque.

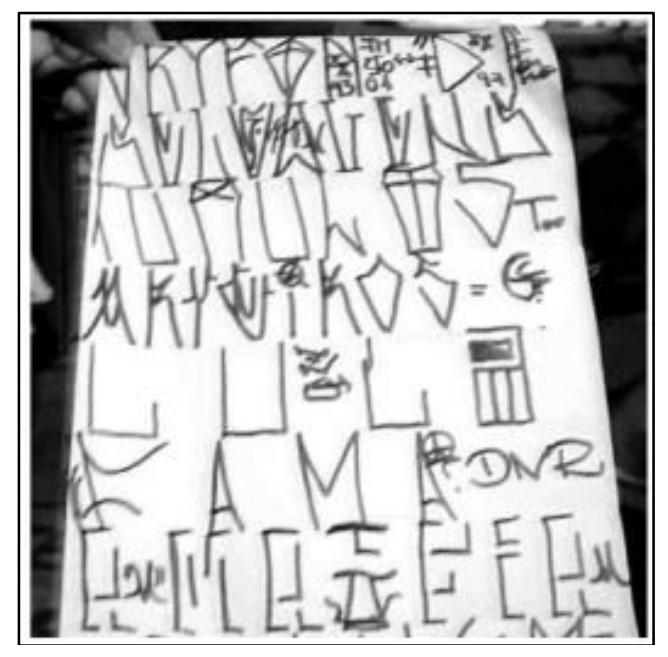

Fonte: PEREIRA, A. B. As marcas da cidade: a dinâmica da pixação em São Paulo. Lua Nova, São Paulo, n. 79 , p. 143-162, 2010.

\footnotetext{
${ }^{13}$ PIRES, Á. O. S. A pichação como apropriação... Op. cit.

${ }^{14}$ Ibidem, p. 87.

15 DOMINGOS, B. S. M.; ELOY, G. O.; FERNANDES, L. F. V. M. Concretos que falam: análise comparativa de grafites sob vias suspensas nas cidades de São Paulo e Lorena/SP. Ponto Urbe [Online], São Paulo, n. 20, 2017, p. 1.

${ }_{16}$ BRASIL. Lei n. 0 12.408, de 25 de Maio de 2011. Altera o art. 65 da Lei no 9.605, de 12 de fevereiro de 1998, para descriminalizar o ato de grafitar, e dispõe sobre a proibição de comercialização de tintas em embalagens do tipo aerossol a menores de 18 (dezoito) anos. Disponível em: http://www.planalto.gov.br/ccivil_03/_Ato2011-2014/2011/Lei/L12408.htm. Acesso em: 16 jun. 2019.
} 
Figura 3 - Prédio pixado em São Paulo.

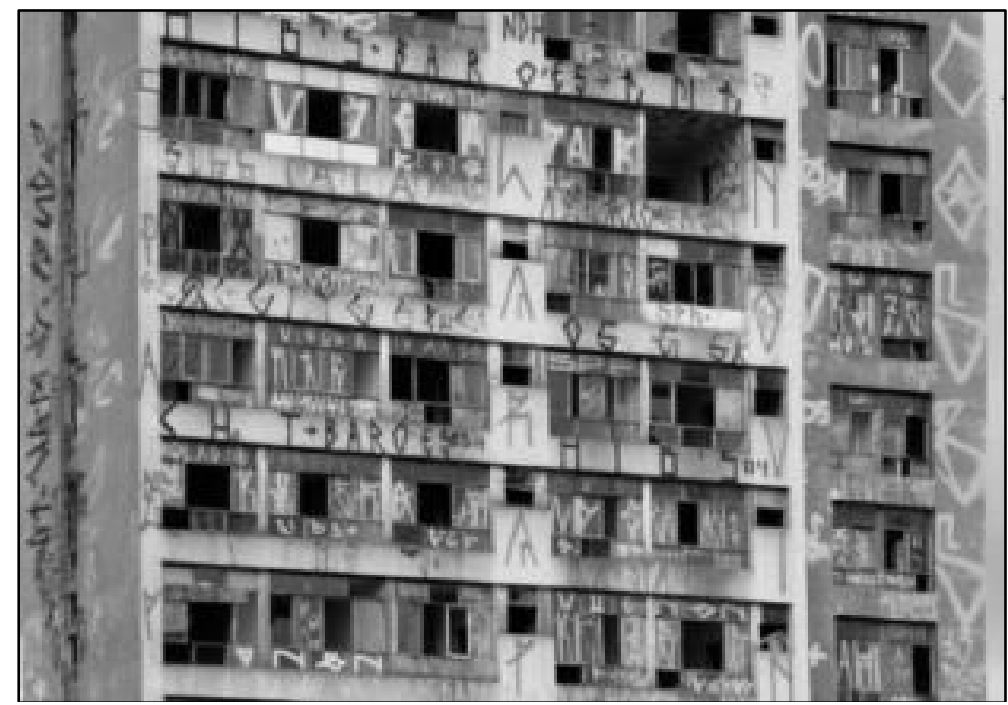

Fonte: PEREIRA, A. B. As marcas da cidade: a dinâmica da pixação em São Paulo. Lua Nova, São Paulo, n. 79, p. 143-162, 2010.

O pixo não é somente efeito da tinta. Entre uma marca e outra nas paredes da cidade existe uma rede de relações carregadas de sentido e de sociabilidades permeadas por outras expressões artísticas urbanas traduzidas na música (Rap e Hip-hop), nos esportes (skate, patins e bicicletas), na poesia (Sarau) e na dança (Break e Street Dance). Segundo Pereira, "apesar de possuir dinâmicas próprias na cidade, pixadores e grafiteiros circulam por um mesmo circuito na cidade: o das artes de rua. Por isso, as relações entre os adeptos das duas expressões visuais são marcadas por aproximações e distanciamentos. Há, inclusive, muitos que são adeptos das duas atividades". ${ }^{17}$

Lassala explica que a pixação é "grafada sempre com o mesmo estilo", possuindo um "grafismo particularizado e padronizado". ${ }^{18}$ A forma como as letras são colocadas tem estreita ligação com o movimento do corpo dos pixadores, pois são feitas à mão livre e de forma rápida, algumas vezes "em condição de pouco equilíbrio e, não raro, na medida da extensão do braço do pixador ou com o seu ângulo de ação ampliado por cabos extensores, circunstâncias que resultam em letras tremidas, tortas, com respingos de tinta e esfumaçadas". ${ }^{19}$ Ainda quanto à tipografia, Finizola define o pixo paulistano como uma "tipografia vernacular", em outras palavras, um estilo de letras autêntico da cultura de um determinado lugar, provenientes de tradições culturais transmitidas de geração para geração, informalmente. ${ }^{20}$

A memória da pixação paulistana está, para além das suas marcas pela cidade, em trabalhos acadêmicos, jornais, revistas, websites e também em documentários. O Pixo (2009),

17 PEREIRA, A. B. Cidade de riscos: notas etnográficas sobre pixação, adrenalina, morte e memória em São Paulo. Revista de Antropologia, São Paulo, USP, v. 56, n. 1, 2013, p. 107.

${ }^{18}$ LASSALA, G. Em nome do pixo... Op. cit., p. 83.

19 Ibidem, p. 81.

${ }^{20}$ FINIZOLA, F. Tipografia vernacular urbana. São Paulo: Blucher, 2010, p. 30. 
dirigido por João Wainer e Roberto T. Oliveira, é um documentário que oferece uma experiência de imersão no universo da pixação paulistana, por retratar com fidelidade a transgressão engendrada nas práticas, bem como os dramas, emoções e intencionalidades.

Figura 4 - Cena do documentário Pixo, em São Paulo.

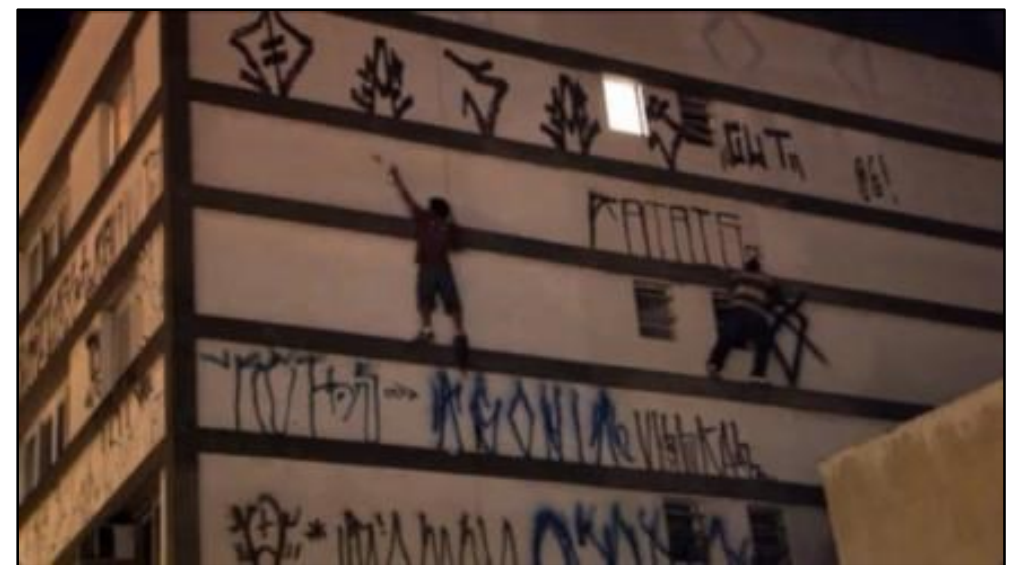

Fonte: Pixo. Direção: João Wainer e Roberto T. Oliveira. São Paulo: Sindicato Paralelo Filmes, 2009. (61 min.), widescreen, color.

Na cidade de São Paulo, a pixação também é posta em dualidade contra o graffiti, que é entendido como arte e considerado por muitos como o patamar mais alto das manifestações estéticas urbanas. A pixação, por um lado, é considerada sujeira e poluição visual e, por outro, como um estágio inferior do graffiti. ${ }^{21} \mathrm{Na}$ visão de Ramos, o graffiti, em relação à pixação, se preocupa com a estética, com a elaboração de signos, agrupando-os e ambientando-os ao suporte, com uma inquietação poética consciente. ${ }^{22}$ Gitahy define que a pichação

é uma guerra feita com tinta, todos se conhecem e se identificam pelo tipo de código pixado. Um grande abaixo-assinado para a posteridade, no qual cada um que participa deixa sua marca. [...] A pixação aparece como uma das formas mais suaves de dar vazão ao descontentamento e à falta de expectativas. ${ }^{23}$

A pixação está enraizada na imagem da cidade de São Paulo e se tornou centro de polêmicas e notícias nos últimos anos devido à "Operação Cidade Linda", que se desenrolou nos anos de 2017 e 2018 e foi cunhada pelo ex-prefeito e atual governador do estado de São Paulo João Dória. Entre uma das ações vinculadas à Operação, o painel de aproximadamente 1 km com graffiti de Eduardo Kobra na Avenida 23 de maio (um dos maiores da América Latina) foi apagado com tinta cinza sob a alegação de que "estavam sujos ou pixados" e que as "áreas (eram) degradadas". Alguns grafittis e pixações foram apagados pessoalmente pelo exprefeito. ${ }^{24}$

\footnotetext{
21 PEREIRA, A. B. As marcas da cidade... Op. cit., p. 143.

22 RAMOS, C. M. A. Grafite, Pichação \& Cia. São Paulo: Annablume, 1994.

23 GITAHY, C. O que é graffiti. Op. cit. , p. 24.

24 DOMINGOS, B. S. M.; ELOY, G. O.; FERNANDES, L. F. V. M. Concretos que falam... Op. cit., p. 1.
} 
Figura 5 - Graffiti de Eduardo Kobra na Av. 23 de maio.

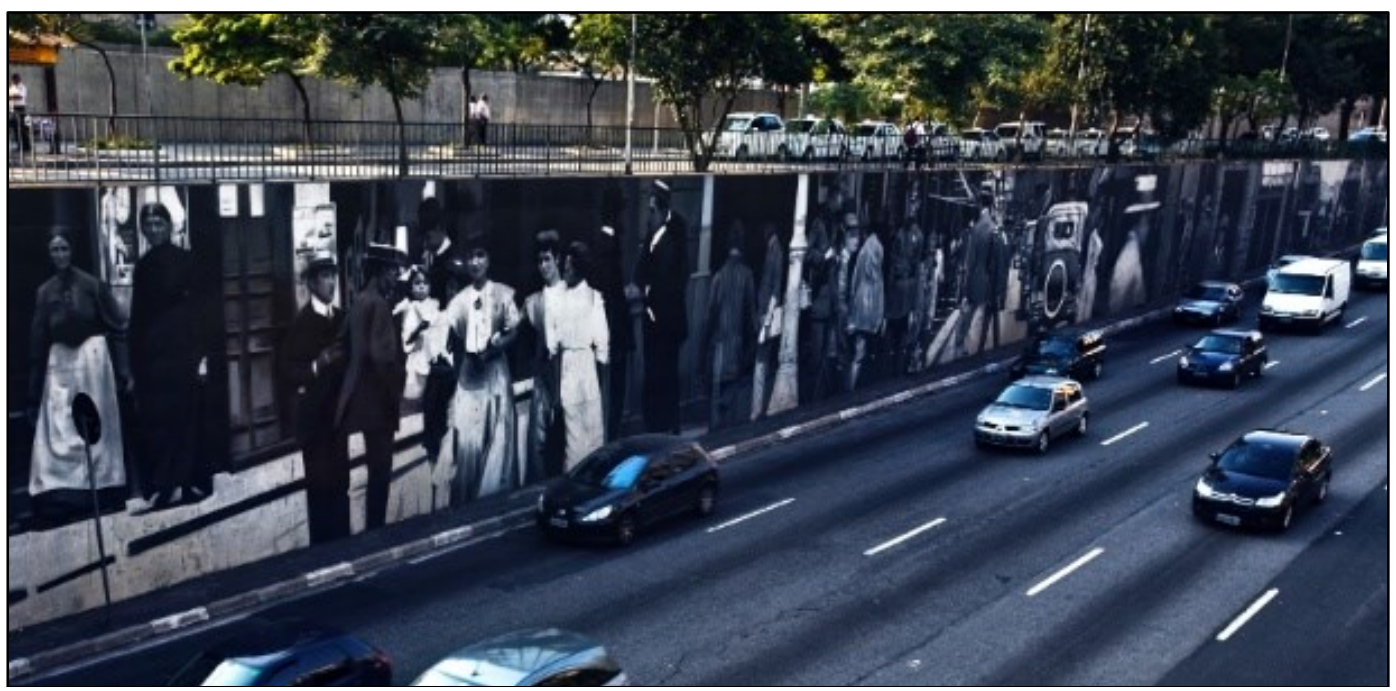

Fonte: Mural de Kobra na Av. 23 de maio é completamente apagado pela prefeitura. Uol. (Site).

Publicado em: 28 jan. 2017. Disponível em: https://noticias.uol.com.br/cotidiano/ultimasnoticias/2017/01/28/mural-de-kobra-na-23-de-maio-e-completamente-apagado-pela-prefeitura-desp.htm. Acesso em: 10 set. 2019.

Figura 6 - Graffiti apagado pela Operação.

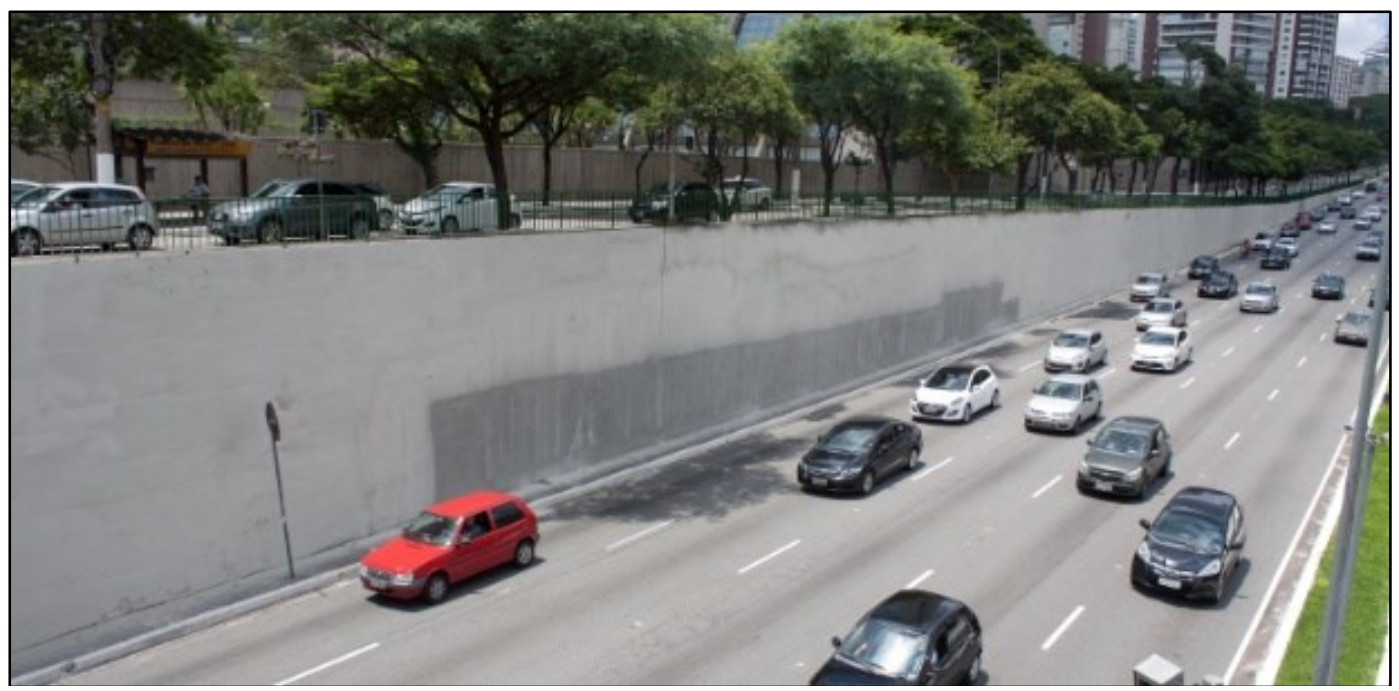

Fonte: Mural de Kobra na Av. 23 de maio é completamente apagado pela prefeitura. Uol. (Site).

Publicado em: 28 jan. 2017. Disponível em: https://noticias.uol.com.br/cotidiano/ultimasnoticias/2017/01/28/mural-de-kobra-na-23-de-maio-e-completamente-apagado-pela-prefeitura-desp.htm. Acesso em: 10 set. 2019.

O termo "linda", da Operação supramencionada, ignora a subjetividade da multiplicidade de percepções estéticas sobre o espaço urbano e seus símbolos, em que a arbitrariedade na decisão por apagar as artes de rua está presente na unilateralidade da decisão, sem consulta à opinião popular (Figura 7). Porém, em fevereiro de 2019, a Justiça de São Paulo condenou João Doria e a Prefeitura pelas remoções dos graffitis da Avenida 23 de Maio. Na decisão, o Juiz alegou que a medida "ocasionou dano ao patrimônio cultural", 
classificando como censura e condenando o pagamento da indenização de $R \$ 782.300$, que será revertida ao Fundo de Proteção do Patrimônio Cultural e Ambiental Paulistano (FUNCAP). ${ }^{25}$

O magistrado, no texto da sua decisão e com uma percepção estética do espaço urbano pautada pela poética, citou os escritores Simone de Beauvoir e Mário de Andrade: "a sensibilidade poética, a meu ver, é a que melhor traduz a dimensão do que se pretende salvaguardar na presente demanda" e completando sua fala com um trecho da música do cantor paulistano Criolo: "Não existe amor em SP/ um labirinto místico/ onde os grafites gritam". 26

Figura 7 - Remoção de pixação em referência ao prefeito João Doria feita pelo artista conhecido como Iaco do muro da Avenida 23 de Maio, em São Paulo.

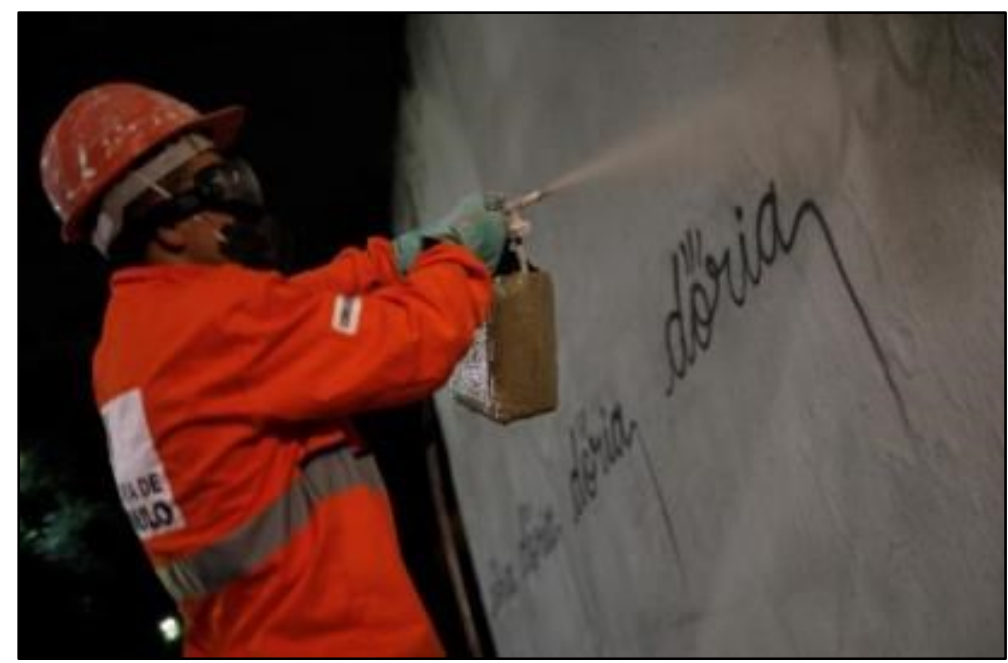

Fonte: A guerra da pichação em São Paulo. G1. (Site). Publicado em: 27 abr. 2017. Disponível em: https://g1.globo.com/sao-paulo/noticia/a-guerra-da-pichacao-em-sao-paulo-fotos.ghtml. Acesso em: 8 set. 2019.

Jean Baudrillard afirma que "tanto muros pintados, como grafites, nasceram após a repressão das grandes revoltas urbanas de 66/70". ${ }^{27}$ Instrumento de resistência histórica nas cidades, a luta no campo das intervenções artísticas urbanas é parte de uma luta mais ampla sobre autoridade, expressão e pertencimento em cidades capitalistas; uma luta sobre quem reivindica o direito de determinar a identidade e possibilidade de lugares urbanos. Nesse enredamento, "a guerra contra o graffiti é um fracasso político", e "a atual política de erradicação e criminalização é contraproducente e dispendiosa, baseada em hipóteses erradas

\footnotetext{
25 PAULO, P. P. Justiça de SP condena Doria e a Prefeitura por remoção de grafites na 23 de Maio. 2019. G1. (Site). Publicado em: 26 fev. 2019. Disponível em: https://g1.globo.com/sp/saopaulo/noticia/2019/02/26/justica-de-sp-condena-doria-e-a-prefeitura-por-remocao-de-grafites-na-23-demaio.ghtml. Acesso em: 8 set. 2019.

${ }^{26}$ Ibidem.

27 BAUDRILLARD, J. Kool Killer ou L'Insurrection par les signes. Paris: Les Partisans du moindre effort, 2005, p. 319.
} 
sobre as ligações entre grafite e crime, e cegueira intencional às dinâmicas culturais e motivações de seus praticantes". ${ }^{28}$

A poesia concreta no concreto transforma a cidade em tela. As pixações guardam íntima relação com a arquitetura da metrópole, em que na dualidade que favorece os graffitis em detrimento das pichações, a retórica é "escancaradamente moralista, em diferenciações entre o que seria feio e bonito, autorizado ou não, colorido ou não, controlável ou não, cravado no alto incompreensível dos prédios". ${ }^{29}$ No final das contas, a repressão promove a pixação ao invés de reprimi-la, "porque a manga furtada ao vizinho é sempre mais gostosa, ou, como belamente sintetiza Armando Silva, "o imaginário rebelde procede contra a repressão, mas a própria repressão é sua profunda verdade".

\section{Um pouco de Ipásia em São Paulo (e vice-versa)?}

A epígrafe sobre Ipásia, que inicia este artigo, remete às pixações nos muros e espaços urbanos que parecem ininteligíveis para alguns. No entanto, essas grafias, que parecem sem sentido para muitos, são fortes evidências de narrativas simbólicas. Ítalo Calvino descreve minuciosamente cada uma de suas 55 cidades. Das cidades invisíveis de Calvino, interessa-nos Ipásia, situada no campo dos símbolos e das linguagens, retratada a seguir:

\section{Ipásia}

De todas as mudanças de língua que o viajante deve enfrentar em terras longínquas, nenhuma se compara à que o espera na cidade de Ipásia, porque não se refere às palavras mas às coisas. Uma manhã cheguei a Ipásia. Um jardim de magnólias refletia-se nas lagoas azuis. Caminhava em meio às sebes certo de encontrar belas e jovens damas ao banho: mas, no fundo da água, caranguejos mordiam os olhos dos suicidas com uma pedra amarrada no pescoço e os cabelos verdes de algas.

Senti-me defraudado e fui pedir justiça ao sultão. Subi as escadas de pórfido do palácio que tinha as cúpulas mais altas, atravessei seis pátios de maiólica com chafarizes. A sala central era protegida por barras de ferro: os presidiários com correntes negras nos pés içavam rochas de basalto de uma mina no sub-solo.

Só me restava interrogar os filósofos. Entrei na grande biblioteca, perdi-me entre as estantes que despencavam sob o peso de pergaminhos encadernados, segui a ordem alfabética de alfabetos extintos, para cima e para baixo pelos corredores, escadas e pontes. Na mais remota sala de papiros, numa nuvem de fumaça, percebi os olhos imbecilizados de um adolescente deitado numa esteira, que não tirava os lábios de um cachimbo de ópio.

- Onde está o sábio? - O fumador apontou para o lado de fora da janela. Era um jardim com brinquedos para crianças: os pinos, a gangorra, o pião. $O$ filósofo estava sentado na grama. Disse:

- Os símbolos formam uma língua, mas não aquela que você imagina conhecer. Compreendi que devia me libertar das imagens que até ali haviam anunciado as coisas que procurava: só então seria capaz de entender a linguagem de Ipásia. Agora basta ouvir o relincho dos cavalos e o estalo dos chicotes para ser tomado por uma trepidação amorosa: em Ipásia, deve-se entrar nas estrebarias e nos haras para ver belas mulheres montadas nas selas com as coxas nuas e botas, e

${ }^{28}$ CRAWLEY, K. Beyond the War on Graffiti: The Right to Visual Expression in Urban Spaces. Griffith Journal of Law \& Human Dignity, Southport (Australia), Special Art Issue, 85-107, 2015, p. 101.

29 ZIBORDI, M. Quase impublicável: obras divergentes, relevantes e, sobretudo, simpáticas à pichação em São Paulo. Comunicação \& Educação, São Paulo, ECA/USP, v. 22, n. 1, p. 127-134, 2017, p. 129; 132. 
que, quando se aproxima um jovem estrangeiro, atiram-no em montes de feno ou serragem e o espremem contra ele os mamilos rijos.

E quando o meu espírito não pede nenhum outro alimento ou estímulo além da música, sei que esta deve ser procurada nos cemitérios: os músicos se escondem nas tumbas; de uma fossa para outra, replicam trinados de flautas, acordes de harpas.

Sem dúvida também em Ipásia chegará o dia em que o meu único desejo será partir. Sei que não devo descer até o porto mas subir o pináculo mais elevado da cidadela e aguardar a passagem de um navio lá em cima. Algum dia ele passará? Não existe linguagem sem engano. ${ }^{30}$

À medida que a leitura sobre a descrição da Cidade Invisível de Ipásia avança, o leitor a vê emoldurada à imagem da cidade de São Paulo. Essas imagens se completam e se entrelaçam visualmente às práticas culturais que suas paisagens urbanas transformam em territórios. Ao longo do livro As Cidades Invisíveis, Ítalo Calvino narra aventuras e desventuras pelo olhar de Marco Polo, tecendo uma narrativa que "quer fazer crer que o vivível não pode estar fora do invivível, embora por vezes invisível". ${ }^{31}$

Cidades Invisíveis nos mostra que "o urbano é feito de uma matéria não manipulável, rebelde, caprichosa, mas nem por isso menos fascinante", gerando uma incrível multiplicidade de imagens e símbolos invisíveis que podem, facilmente, se correlacionar com o visível. ${ }^{32}$

A poética do espaço expressa na manhã em que Calvino chega à Ipásia, quando "um jardim de magnólias refletia-se nas lagoas azuis" suscita a imagem em sua origem, em sua essência, em sua pureza. ${ }^{33}$ Por meio de um caso de amor pelo espaço, Gaston Bachelard nos explica que é por meio dele que se pode chegar a uma Fenomenologia da Imaginação. A imagem poética do espaço, para Bachelard, possui transubjetividades que tocam diversas consciências transitáveis em planos artísticos, estéticos, sensíveis e poéticos. ${ }^{34} \mathrm{~A}$ obra do autor, como ressalta Silva, "é um tratado sobre o ser, porque mergulha nas entrelinhas da relação psicoemocional, afetiva, sensitiva, estabelecida entre os polos homem-espaço", em que mesmo com enfoque em espaços íntimos - como a casa/lar, ainda cabe abstrações macro. ${ }^{35}$

Em "as cidades e os símbolos" de Cidades Invisíveis, Calvino apresenta uma cidade a ser lida levando em conta sua densidade e enigmas. Hillman, em seu livro Cidade e Alma, fala que "a alma precisa de suas imagens e, quando não as encontra, elabora substitutos: cartazes de rua e grafite", por exemplo:

Essas marcas feitas em lugares públicos, chamadas de deformação de monumentos, na verdade impõem uma forma pessoal numa parede impessoal ou numa estátua monumental. A mão humana parece querer tocar e deixar seu toque, mesmo que apenas através de manchas obscenas ou rabiscos horríveis [...] Certamente, as grandes obras da engenharia e da inspiração arquitetônica

\footnotetext{
30 CALVINO, I. As cidades invisíveis. Op. cit., p. 21-22.

31 ALVES, L. R. A cidade invisível, de Calvino: os modos de organizar e visibilizar o vivível. Estud. Av., São Paulo, v. 29, n. 85, p. 327-340, dez. 2015, p. 331.

32 MONTEIRO, E. Z. Cidades invisíveis visitadas. Uma leitura de Ítalo Calvino para compreender a paisagem urbana. Resenhas Online, São Paulo, ano 08, n. 085.02, jan. 2009, p. 1.

33 CALVINO, I. As cidades invisíveis. Op. cit., p. 21.

34 BACHELARD, G. A poética do espaço. São Paulo: Martins Fontes, 1993.

35 SILVA, F. Geografia e poesia lírica: considerações sobre a obra "A poética do espaço de Gaston Bachelard". GEOUSP Espaço e Tempo, São Paulo, v. 19, n. 1, p. 60-75, 2015, p. 65.
} 
não seriam espoliadas pela presença de imagens que refletem a "alma" através da mão. ${ }^{36}$

É possível evocar nas cidades que compõem "as cidades e os símbolos" a questão central de Kevin Lynchem, em seu clássico livro A imagem da cidade, cuja "questão central é a compreensão da cidade a partir do seu vocabulário visual, sua linguagem". ${ }^{37}$ Tomando-se Ipásia e São Paulo como suportes para reflexão do fenômeno urbano, é possível traçar conexões entre as imagens da cidade e o imaginário social, "considerando o espaço urbano um lugar privilegiado de intercâmbio material e simbólico do habitante". ${ }^{38}$

Em cada contexto os grafos nas paredes apresentam particularidades e a pixação encontra sua característica na confluência de fatores variados - estética, suporte, situação de produção e comportamento de seus praticantes - que a conformam como um modo de vida e uma forma de experimentar a cidade. ${ }^{39}$

Compreender como o pixo pode estar presente no nosso cotidiano e como o percebemos nas experiências citadinas nos leva a pensar, sobretudo, como o sentimos. A sensibilidade estética nos espaços urbanos está diretamente correlacionada ao corpo, entendido a partir do recurso da filosofia atrelada às ciências sociais. Para dar sentido à Fenomenologia da Percepção, suporte de análise emprestado de Merleau-Ponty, afirmamos que as experiências nascem do reconhecimento e da compreensão subjetiva e objetiva do "ser no mundo". ${ }^{40}$

Nóbrega afirma que, em pinturas como de Matisse ou Cézanne, "o mundo não está diante do artista por representação, mas como acontecimento febril, uma encruzilhada onde o chão, assim como as linhas, os contornos, deslizam sob os nossos pés". ${ }^{41}$ Entre as tessituras visíveis e invisíveis propostas nas relações entre Ipásia e São Paulo, a "percepção é uma porta aberta a vários horizontes; porém, é uma porta giratória, de modo que, quando uma face se mostra, a outra se torna invisível" ${ }^{42}$ Olhamos o mundo real, mas sob esse olhar se desvelam inúmeros significados.

Pelo viés fenomenológico da imaginação (de Bachelard) e da percepção (de MerleauPonty), a dimensão existencial humana está atrelada à materialidade que o espaço nos apresenta. Construímos e habitamos a cidade. ${ }^{43} \mathrm{~A}$ forma dos espaços urbanos deriva das vivências corporais. Sennet também expressa seu entendimento pela necessidade da mudança do nosso entendimento a respeito do corpo. No livro Carne e Pedra, o autor reconta a história da cidade a partir da experiência corporal do povo, seguindo a mesma dinâmica de As Cidades

\footnotetext{
${ }^{36}$ HILLMAN, J. Cidade \& Alma. São Paulo: Studio Nobel, 1993, p. 40-41.

${ }^{37}$ LYNCH, K. A imagem da cidade. Op. cit.; MONTEIRO, E. Z. Cidades invisíveis visitadas... Op. cit., p. 2.

${ }^{38}$ CALDEIRA, S. P. A Cidade Personagem: Pina Bausch e Ítalo Calvino. Revista de C. Humanas, v. 7, n. 2, p. 147-162, 2007, p. 147.

39 PIRES, Á. O. S. A pichação como apropriação... Op. cit., p. 27.

40 MERLEAU-PONTY, M. Fenomenologia da percepção. São Paulo: Martins Fontes, 2006.

41 NOBREGA, T. P. Corpo, percepção e conhecimento em Merleau-Ponty. Estud. psicol. (Natal), Natal, v. 13 , n. 2, p. 141-148, 2008, p. 142.

42 Ibidem, p. 145.

43 RAMOS, V. G.; CAMPOS, M. M. Práticas urbanas e a fenomenologia. Anais do [...]. XVIII Encontro Nacional da Associação Nacional de Pós-Graduação e Pesquisa em Planejamento Urbano e Regional. Natal: ENANPUR, 2019.
} 
Invisíveis, ao perpassar por diversas cidades na construção das narrativas. ${ }^{44}$ Sensibilizar-se com a cidade perpassa primeiro pela subjetividade. Para Merleau-Ponty, "o mundo é aquilo que nós percebemos", e "o mundo é não aquilo que eu penso, mas aquilo que eu vivo: eu estou aberto ao mundo, comunico-me indubitavelmente com ele, mas não o possuo, ele é inesgotável". ${ }^{45}$

As leituras da paisagem urbana demandam, além da lente fenomenológica, a semiótica. Espaços e sujeitos são os polos de uma relação que os precede e os transcende. De acordo com Marrone, "o todo no interior de uma história e de uma memória atenua as forças entrópicas do tempo, consolidando homens e coisas, construindo e mantendo retalhos de identidades". ${ }^{46}$ Os signos da paisagem da cidade constituem entendimentos sobre o lugar, o espaço e o território, em um desdobramento contínuo de interpretação e de significação:

A cognição visual, como principal sentido, está no entendimento daquilo que o indivíduo vê. Contudo, ela acontece aos poucos e abrange as demais percepções, interagindo com fenômenos fisiológicos e psicológicos, enquanto as sensações vão se produzindo e sendo organizadas na mente dos indivíduos. Assim, a análise sob a perspectiva de significação é contínua, assegurando um modo de apreensão dos significados, tanto nos aspectos perceptíveis, quanto nos emocionais. Em outras palavras, é possível relacionar significados corporificados no espaço urbano com aqueles que existem apenas no imaginário das pessoas. ${ }^{47}$

Os signos descritos na cidade de Ipásia criam uma dentre outras representações culturais daquele local; afinal, "não existe linguagem sem engano". ${ }^{8}$ Por detrás de toda linguagem de uma intervenção artística permeiam intencionalidades, que se revelam na escolha do local, da temática, do tamanho do suporte, das ilustrações (ou tipografias), das cores e dos traços. Karina Puente desenvolveu uma série de ilustrações sobre as cidades de Ítalo Calvino.

Figura 8 - Composição da ilustração da cidade de Ipásia.
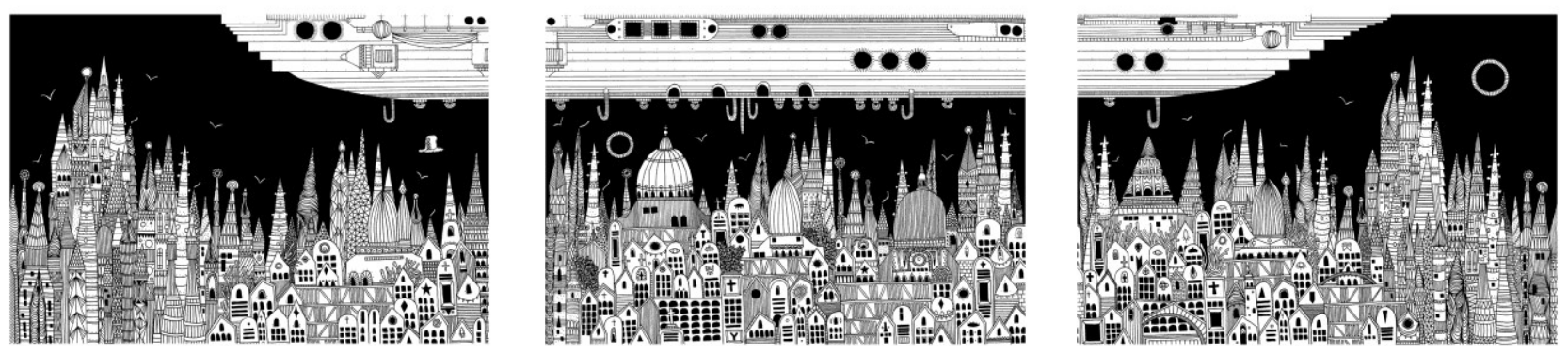

Fonte: PUENTE, K. Ilustração da Cidade de Ipásia. Disponível em:

http://karinapuente.com/index\#/ipazia-city-1. Acesso em: 26 maio 2019.

\footnotetext{
44 SENNET, R. Carne e pedra: o corpo e a cidade na civilização ocidental. Rio de Janeiro: BestBolso, 2016.

${ }^{45}$ MERLEAU-PONTY, M. Fenomenologia da percepção. Op. cit., p. 14.

46 MARRONE, G. Semiótica da cidade: corpos, espaços, tecnologias. Galaxia (São Paulo, Online), n. 29, 28-43, jun. 2015, p. 29.

47 MAZIERO, L. T. P.; BONAMETTI, J. H. Espaço urbano como comunicação: Signos da paisagem. Revista de Estudos da Comunicação, Curitiba, v. 14, p. 463-478, 2013, p. 476-477.

${ }^{48}$ CALVINO, I. As cidades invisíveis. Op. cit., p. 22.
} 
Como não existe linguagem sem engano, Gitahy afirma que as pixações têm o intuito de interferir em muros, monumentos e fachadas arquitetônicas com rabiscos, frases de protestos, insultos, que leigos não conseguem decifrar, como uma forma de identificação e demarcação de territórios entre grupos, algumas vezes, rivais. ${ }^{49}$ Oliveira reflete sobre o modo como os pixadores jogam com o legível e o ilegível em suas inscrições ao dizer que a forma das letras de difícil decifração "é apresentada como um dificultador por ser ilegível à maioria das pessoas. As inscrições se configuram como um saber próprio, uma espécie de alfabeto particular, que pode ser aprendido, como qualquer outro". Porém, os pichadores fazem dessa dinâmica um jogo, em que deixam "legíveis os textos que eles querem que sejam lidos por todos" ao passo que mantém "a própria escrita para suas assinaturas e de seus grupos". Dessa forma, "suas demandas acabam sendo quase que arbitrariamente ignoradas". ${ }^{50}$ Caldeira enfatiza que:

o sujeito que lê e interpreta as cidades faz-se um detetive de subtrações, de ausências. Subtrai das narrativas urbanas a ideia de utopia, a visão una organizada e totalizante do país, a cidade compartilhada, as marcas identitárias exclusivas e singulares da própria cidade, e de homens, e mulheres nesse espaço plural e fragmentário. ${ }^{51}$

Nesse jogo entre o que a pixação visível tem de invisível e o que a cidade invisível de Ipásia tem de visível, "o graffiti/pixação já traz per se várias camadas de potenciais imaginários [...]. Tal cultura porta signos ou imagens nas quais a interpretação e a imaginação agem de várias maneiras, sendo intermediária entre o concreto e o conceito". ${ }^{52}$

O livro As Cidades Invisíveis apresenta uma multiplicidade de urbes que se dividem entre cidades desperdiçadas, as encontradas e procuradas, as idealizadas e as perdidas, nessa última situando-se Ipásia/As cidades e os símbolos no espaço. A Figura 9 apresenta um diagrama que nos auxilia a situar as cidades em planos e/ou espaços. A linha horizontal que divide o gráfico em "terra-céu" mostra que as "cidades ocultas", "e os símbolos", "e os nomes", "e os mortos" estão em certo sentido "perdidas": "perdidas no tempo, ou na memória, ou fisicamente enterradas no espaço. Ou ainda, incompreendidas ou incompreensíveis", caso de Ipásia. ${ }^{53}$

\footnotetext{
${ }^{49}$ GITAHY, C. O que é graffiti. Op. cit.

50 OLIVEIRA, A. K. C. "Agora é a vez do pixo": cenas de dissenso e subjetivação política nas relações entre pixação e arte. 2015. Dissertação (Mestrado em Comunicação Social) - Universidade Federal de Minas Gerais, Belo Horizonte, p. 88.

${ }^{51}$ CALDEIRA, S. P. A Cidade Personagem... Op. cit., p. 147-148.

52 BORGES, Z. N.; GARRABÉ, L.; DANTAS, R. N. R. Etnografia de uma cidade redesenhada pela pichação/graffiti. Revista de Ciências Sociais, Fortaleza, v. 46, n. 1, jan.-jun. 2015, p. 120.

53 MONTEIRO, E. Z. Cidades invisíveis visitadas... Op. cit. , p. 3.
} 
Figura 9 - Proposta de visualização dos onze grupos de cidades do livro As Cidades Invisíveis.

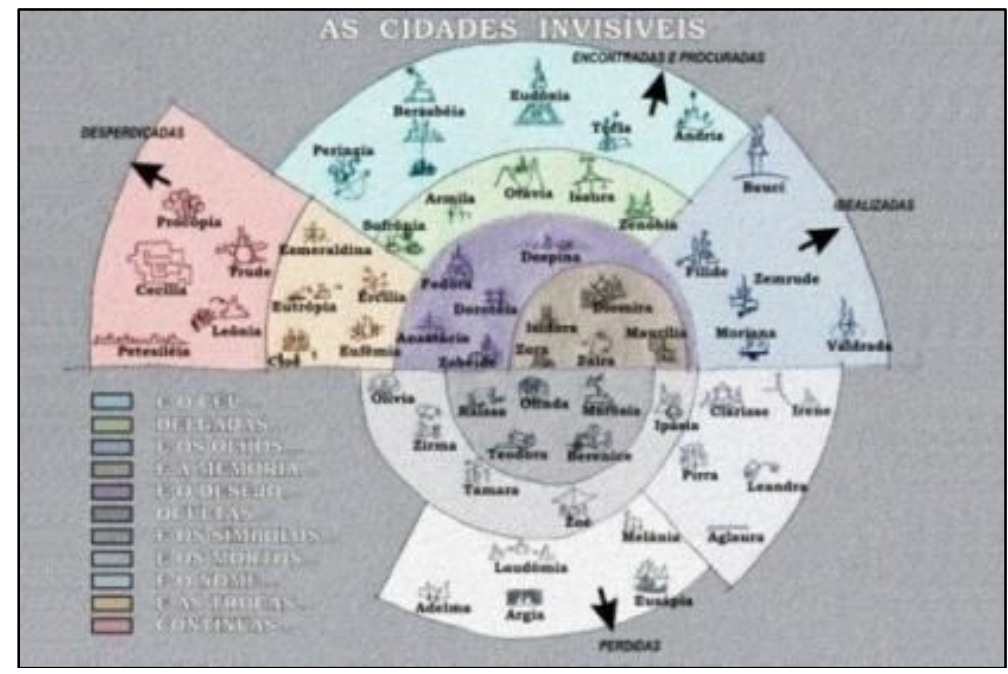

Fonte: MONTEIRO, E. Z. Cidades invisíveis visitadas. Uma leitura de Ítalo Calvino para compreender a paisagem urbana. Resenhas Online, São Paulo, ano 08, n. 085.02, jan. 2009, p. 3.

A leitura da obra de Ítalo Calvino nos impõe o exercício de compreendermos e agirmos no real suscitados pelo suporte da imaginação, como formas de vislumbrarmos possibilidades no campo das ações, pois, conforme ressaltou Bachelard, "a imaginação aumenta os valores da realidade". ${ }^{54}$ As cidades invisíveis, de Ítalo Calvino, "nos presenteiam não a comodidade das metáforas indicadoras de realidades familiares, mas com virtualidades de ações, narrativas incompletas, desassossegos produtores de mundos possíveis ou impossíveis, que têm o corpo da cidade como fundamento singular". ${ }^{55}$

Portanto, os nexos entre Ipásia e São Paulo ficam evidentes por meio das simbologias impressas em seus territórios e práticas, entre o que é visível e o invisível. Os pixos de São Paulo se correlacionam com os de Ipásia, cujos "símbolos formam uma língua, mas não aquela que você imagina conhecer"; no entanto, adverte o autor, "não existe linguagem sem engano". ${ }^{56}$ A língua incompreensível presente na cidade imaginária de Ipásia se assemelha à pixação paulistana ao passo que nem todos os habitantes da urbe conseguem ler as tags e letras de traços retos, mas que, mesmo diante da incompreensão, são produzidos sentidos e laços identitários entre espaço-homem, transbordando qualquer leitura superficial da realidade.

Nas pontes teórico-metodológicas tecidas entre a cidade imaginária e a real, proposta por esse artigo, a Fenomenologia da Percepção, de Merleau-Ponty, nos mostrou que as experiências nascem do reconhecimento e da compreensão subjetiva e objetiva do "ser no mundo". ${ }^{57}$ Pela Fenomenologia da Imaginação de Bachelard, vimos ser essencial conhecer a imagem em sua origem, em sua essência, em sua pureza. Ler a "paisagem" pelo viés dos

\footnotetext{
54 BACHELARD, G. A poética do espaço. Op. cit., p. 357.

55 CALDEIRA, S. P. A Cidade Personagem... Op. cit., p. 158.

${ }^{56}$ CALVINO, I. As cidades invisíveis. Op. cit., p. 21-22.

57 MERLEAU-PONTY, M. Fenomenologia da percepção. Op. cit.
} 
símbolos, do imaginário, das subjetividades, buscando a semiótica do ambiente simbólico e da fenomenologia implica em novos olhares sobre espaços que percorremos cotidianamente. No caso do pixo, significa olhar sua tipografia, suas formas, sua legibilidade, sua posição no espaço e o tempo, dimensões indissociáveis da inteligibilidade da realidade concreta, cujo exercício de interpretação nos convida a nos libertar das imagens que anunciam as coisas que procuramos. ${ }^{58}$

Nesta perspectiva, o espaço emerge permeado de significações materiais e imateriais, proporcionando sentimentos e sensações que conectam as pessoas aos lugares. Desse modo, a produção de identidades territoriais, fortemente ligado à pixação e a Ipásia, encontra uma de suas centralidades nos símbolos. Por esse viés, os símbolos, na forma de pixação são, de certo modo, parte da experiência de se visitar/viver em São Paulo. Entre símbolos e significados, Ipásia e São Paulo dialogam com o urbano real e o imaginado.

${ }^{58}$ BACHELARD, G. A poética do espaço. Op. cit. 


\section{Referências}

ALVES, L. R. A cidade invisível, de Calvino: os modos de organizar e visibilizar o vivível. Estud. Av., São Paulo, v. 29, n. 85, p. 327-340, dez. 2015. http://www.scielo.br/scielo.php?script=sci_arttext\&pid=S0103$40142015000300022 \& \operatorname{lng}=e n \& n r m=i s o$. Acesso em: 16 jun. 2019.

BACHELARD, G. A poética do espaço. São Paulo: Martins Fontes, 1993.

BAUDRILLARD, J. Kool Killer ou L'Insurrection par lessignes. Paris: Les Partisans du moindre effort, 2005.

BORGES, Z. N.; GARRABÉ, L.; DANTAS, R. N. R. Etnografia de uma cidade redesenhada pela pichação/graffiti. Revista de Ciências Sociais, Fortaleza, v. 46, n. 1, p. 119-141, jan.-jun. 2015.

BRASIL. Lei No 12.408, de 25 de Maio de 2011. Altera o art. 65 da Lei no 9.605, de 12 de fevereiro de 1998, para descriminalizar o ato de grafitar, e dispõe sobre a proibição de comercialização de tintas em embalagens do tipo aerossol a menores de 18 (dezoito) anos. Disponível em: http://www.planalto.gov.br/ccivil_03/_Ato2011-2014/2011/Lei/L12408.htm. Acesso em: 16 jun. 2019.

CALDEIRA, S. P. A Cidade Personagem: Pina Bausch e Ítalo Calvino. Revista de C. Humanas, v. 7, n. 2, p. 147-162, 2007. Disponível em: www.cch.ufv.br/revista/pdfs/vol7/artigo1vol7-2.pdf. Acesso em: 16 jun. 2019.

CALVINO, I. As cidades invisíveis. São Paulo: Companhia das Letras, 1990.

CARERI, F. Walkscapes, o caminhar como prática estética. Barcelona: Gustavo Gili, 2013.

CRAWLEY, K. Beyond the War on Graffiti: The Right to Visual Expression in Urban Spaces. Griffith Journal of Law \& Human Dignity, Southport (Australia), Special Art Issue, p. 85-107, 2015.

DOMINGOS, B. S. M.; ELOY, G. O.; FERNANDES, L. F. V. M. Concretos que falam: análise comparativa de grafites sob vias suspensas nas cidades de São Paulo e Lorena/SP. Ponto Urbe [Online], São Paulo, v. 20, 2017. Disponível em: http://journals.openedition.org/pontourbe/3426. Acesso: 16 jun. 2019.

FILARDO, P. R. Pichação (pixo). Histórico (tags), práticas e a paisagem urbana. Arquitextos, São Paulo, ano 16, n. 187.00, dez. 2015. Disponível em: http://www.vitruvius.com.br/revistas/read/arquitextos/16.187/5881. Acesso em: 16 jun. 2019.

FINIZOLA, F. Tipografia vernacular urbana. São Paulo: Blucher, 2010.

GITAHY, C. O que é graffiti. São Paulo: Brasiliense, 1999.

HILLMAN, J. Cidade \& Alma. São Paulo: Studio Nobel, 1993.

LASSALA, G. Em nome do pixo: a experiência social e estética do pichador e artista DjanIvson. 2014. Tese. (Doutorado em Arquitetura e Urbanismo) - Universidade Presbiteriana Mackenzie, São Paulo.

LYNCH, K. A imagem da cidade. Lisboa: Edições 70, 1970.

MARRONE, G. Semiótica da cidade: corpos, espaços, tecnologias. Galaxia (São Paulo), n. 29, p. 28-43, jun. 2015.2 Disponível em: 
https://www.scielo.br/scielo.php?script=sci_arttext\&pid=S1982-

$25532015000100028 \&$ Ing=pt\&tlng=pt. Acesso em: 16 jun. 2019.

MAZIERO, L. T. P.; BONAMETTI, J. H. Espaço urbano como comunicação: Signos da paisagem. Revista de Estudos da Comunicação, Curitiba, v. 14, p. 463-478. 2013.

MERLEAU-PONTY, M. Fenomenologia da percepção. São Paulo: Martins Fontes, 2006.

NOBREGA, T. P. Corpo, percepção e conhecimento em Merleau-Ponty. Estud. Psicol. (Natal), Natal, v. 13, n. 2, p. 141-148, 2008. Disponível em: http://www.scielo.br/scielo.php?script=sci_arttext\&pid=S1413-

294X2008000200006\&lng=en\&nrm=iso. Acesso em: 8 set. 2019.

MONTEIRO, E. Z. Cidades invisíveis visitadas. Uma leitura de Ítalo Calvino para compreender a paisagem urbana. Resenhas Online, São Paulo, ano 08, n. 085.02, jan. 2009. Disponível em: http://www.vitruvius.com.br/revistas/read/resenhasonline/08.085/3050. Acesso em: 16 jun. 2019.

OliVeIRA, A. K. C. "Agora é a vez do pixo": cenas de dissenso e subjetivação política nas relações entre pixação e arte. 2015. Dissertação (Mestrado em Comunicação Social) Universidade Federal de Minas Gerais, Belo Horizonte.

PEREIRA, A. B. Cidade de riscos: notas etnográficas sobre pixação, adrenalina, morte e memória em São Paulo. Revista de Antropologia, São Paulo, USP, v. 56, n. 1, 2013.

PEREIRA, A. B. As marcas da cidade: a dinâmica da pixação em São Paulo. Lua Nova, São Paulo, $\quad$ n. 79, p. 143-162, 2010. Disponível em: http://www.scielo.br/scielo.php?script=sci_arttext\&pid=S010264452010000100007\&lng=en\&nrm=iso. Acesso em : 24 jun. 2019.

PIRES, Á. O. S. A pichação como apropriação da cidade: o pixador como formador do cenário urbano. 2017. Dissertação (Mestrado em História Social da Cultura) - Universidade Federal de Minas Gerais, Belo Horizonte.

PUENTE, K. Ilustração da Cidade de Ipásia. Disponível em: http://karinapuente.com/index\#/ipazia-city-1. Acesso em: 26 maio 2019.

RAMOS, C. M. A. Grafite, Pichação \& Cia. São Paulo: Annablume, 1994.

RAMOS, V. G.; CAMPOS, M. M. Práticas urbanas e a fenomenologia. Anais do [...]. XVIII Encontro Nacional da Associação Nacional de Pós-Graduação e Pesquisa em Planejamento Urbano e Regional. Natal: ENANPUR, 2019.

SANTOS, M. Metamorfoses do espaço habitado. Fundamentos teóricos e metodológicos da Geografia. São Paulo: Hucitec. 1996.

SENNET, R. Carne e pedra: o corpo e a cidade na civilização ocidental. Rio de Janeiro: BestBolso, 2016.

SILVA, F. Geografia e poesia lírica: considerações sobre a obra "A poética do espaço de Gaston Bachelard". GEOUSP Espaço e Tempo, São Paulo, v. 19, n. 1, p. 60-75, 2015.

SILVA, F. L.; ZANETTI, V. São José dos Campos: cidade e graffiti enclausurados (2003-2009). Anais do [...]. XIII Encontro Latino Americano de Iniciação Científica. São José dos Campos: Universidade do Vale do Paraíba, 2009.

ZIBORDI, M. Quase impublicável: obras divergentes, relevantes e, sobretudo, simpáticas à pichação em São Paulo. Comunicação \& Educação, São Paulo, ECA/USP, v. 22, n. 1, p. 127$134,2017$. 